Diánoia, vol. 9, no. 9, 1963

\title{
INCALIFICACIÓN E INDIFERENCIA ${ }^{1}$
}

\section{Introducción. Incalificación de los comportamientos e integridad de los ordenamientos}

Defino 'incalificación': Incalificación es la cualidad del comportamiento que ninguna norma de un ordenamiento normativo califica según uno de Ios modos deónticos "obligatorio", "prohibido", "indiferente".

Defino los modos deónticos. Asumo como modo indefinido, en cuyos términos defino los otros, el modo deóntico "permitido". Todos los modos se definen unitariamente en los términos de permisión o no permisión de la comisión o de la omisión de los comportamientos. Permitido es el comportamiento del cual está perrnitida la comisión. Facultativo es el comportamiento del cual está permitida la omisión. Obligatorio es el comportamiento del cual está permitida la comisión, y no está permitida la omisión. Prohibido es el comportamiento del cual no está permitida la comisión, y está permitida la omisión. Indiferente es el comportamiento del cual está permitida la comisión y está permitida la omisión. ${ }^{2}$ Imperativo es el comportamiento que es $u$ obligatorio o prohibido; o sea (traduciendo y reduciendo a términos de "permitido"), el comportamiento del cual o está permitida la comisión, y no está permitida la omisión, o no está permitida la comisión, y está permitida la omisión. Las relaciones de oposición entre los juicios deónticos pueden representarse mediante un hexágono de oposición análogo al cuadrado de oposición. El juicio deóntico, que califica a un comportamiento como obligatorio, es el contradictorio del juicio que califica como permitida la omisión de ese comportamiento (es decir, que califica aquel comportamiento como facultativo). El juicio deóntico, que califica como prohibido, es el contradictorio del juicio que califica como permitido. El juicio deóntico, que califica como imperativo, es el contradictorio del juicio que califica como indiferente. El modo deóntico "indiferente" debe distinguirse de otros modos y de otros predicados. 'Indiferente' no es sinó-

1. El presente artículo enuncia algunas de las tesis expresadas por el autor en Saggio sulla completezza degli ordinamenti giuridici. Torino, G. Giappichelli, 1962, págs. XIV-234 ("Università di Torino, Memorie dell' Instituto giuridico", serie 2, memoria 111).

2 En el uso de "indiferente" sigo a Georg Henrik von Wright, "Deontic Logic", Mind, New Series, 6o, 1961, pp. 1-15; ensayo que ha. sido reeditado en idem, Logical Studies, Amsterdam, North-Holland Publishing Company, $195^{1}$.

Uso 'indiferente' e 'indiferencia', y no 'lícito' y 'licitud' que son, sin embargo, términos más usuales entre los juristas, por dos motivos: en primer lugar, porque 'lícito' es a veces sinónimo de 'permitido', en tanto que 'indiferente' no es nunca sinónimo de 'permitido'; en segundo lugar, porque 'ilícito' es siempre sinónimo de 'prohibido', en tanto que 'no indiferente' nunca es sinónimo de 'prohibido', sino de 'imperativo'. 
nimo ni de 'permitido', ni de 'facultativo', ni de 'irrelevante', ni de 'incalificado'. 'Indiferente' no és sinónimo de 'permitido': permitido es el comportamiento del cual están permitidas la comisión y la omisión. 'Indiferente' no es sinónimo de 'facultativo': facultativo es el comportamiento del cual está permitida la omisión; indiferente es el comportamiento del cual están permitidas la comisión y la omisión. 'Indiferente' no es sinónimo de 'irrelevante': irrelevante es el comportamiento que, con un juicio de valor de lege ferenda, se juzga indigno de calificación deóntica; indiferente es el comportamiento que, con un juicio de hecho de lege lata, se juzga calificado según el modo deóntico "indiferente". "Indiferente" no es sinónimo de 'incalificado': lo incalificado carece de status deóntico; lo indiferente es un status deóntico; el comportamiento incalificado no tiene un status deóntico; el comportamiento indiferente tiene un status deóntico (el de indiferente, el status deóntico llamado indiferencia). La definición unitaria de los modos deónticos en términos de "permitido", la traducción unitaria de los juicios deónticos en términos de permisión o. no permisión de la comisión o de la omisión de los comportamientos, permiten responder a la antigua pregunta sobre cuáles y cuántos soñ los modos deónticos. Nueve son las situaciones deónticas combinatoriamente posibles: I) está permitida la comisión, está permitida la omisión; 2) está permitida la comisión, no está permitidá la omisión; 3) no está permitida la comisión, está permitida la omisión; 4) no está permitida la comisión, no está permitida la omisión; 5) está permitida la comisión, la omisión está incalificada; 6) la comisión éstá incalificada, está permitida la omisión; 7) no está permitida la comisión, la omisión está incalificada; '8) la comisión está incalificada, no está permitida la omisión; 9) la comisión está incalificada, la omisión está incalificada. Nueve, por tanto, son las combinaciones posibles. En la primera, el comportamiento es indiferente; en la segunda, obligatorio; en la tercera, prohibido; en la cuarta, prohibido y obligatorio; en la quinta, permitido; en la sexta, facultativo; en la séptima, prohibido; en la octava, obligatorio; en la novena, incalificado.

Nueve son las combinaciones posibles. Tres los status deónticos, o sea, las condiciones de aquellos comportamientos de los cuales están calificadas ya sea la comisión, ya sea la omisión (obligatoriedad, prohibición, indiferencia). Uno el Urmodus deóntico indefinido definiente ("permitido").

Defino 'laguna', 'antinomia', 'no integridad', 'integridad'. Hay laguna si, cuando menos de un comportamiento, o la comisión o la omisión no están ni permitidas ni no permitidas. Hay antinomia si, cuando menos de un comportamiento, o la comisión o la omisión eśtán permitidas y no permitidas. Hay no integridad si cuando menos hay una laguna. Hay integridad si no hay laguna. "Integridad" significa, por tanto, la propiedad de un ordenamiento normativo que califica deónticamente (según uno de los mo- 
dos deónticos) ya sea la comisión, ya sea la omisión de cualquier posible comportamiento. Integridad es la cualidad de un ordenamiento que deriva de sí, y sólo de sí, la calificación deóntica de la comisión y de la omisión de todos los comportamientos.

Formulo el problema de la integridad. Supongamos unos comportamientos incalificados. En otros términos, supongamos unos comportamientos que ninguna norma del ordenamiento califica como $u$ obligatorios, $o$ prohibidos, $o$ indiferentes. Ahora, un ordenamiento es completo si todo comportamiento es u obligatorio, o prohibido, o indiferente. (O, en términos más rigurosos, un ordenamiento es completo si con respecto a ningún comportamiento o la comisión o la omisión no están ni permitidas ni no permitidas.) ¿Cuál es la relación entre la presencia de los comportamientos incalificados y la integridad del ordenamiento? ¿Cuál es la relación entre la incalificación de los comportamientos y la integridad de los ordenamientos normativos? ¿Tiene un status deóntico el mismo comportamiento incalificado? Y si acaso tiene uno ¿cuál? ¿Cuál es el status deóntico del comportamiento al cual ninguna norma le atribuye uno? ¿Está (ist) calificado el mismo comportamiento que no llega a ser (wird) calificado?

De diferentes maneras puede intentarse fundamentar la integridad de los ordenamientos normativos. De las fundamentaciones posibles, pretendo aqui formular y valorar dos fundamentaciones: la fundamentación en el principio del tercio excluso, y la fundamentación en la lógica deóntica.

Formulo en seguida mi tesis: las dos fundamentaciones o no instauran la integridad, o instauran la contradictoriedad. O lagunas, o antinomias.

\section{La fundamentación de la integridad en el principio del tercio excluso.}

\subsection{La fundamentación.}

Según la fundamentación de la integridad en el principio del tercio excluso, la integridad subsiste necesaria y a priori para todo ordenamiento y para todo comportamiento. Para todo ordenamiento: por tanto, no para algunos ordenamientos. Para todo comportamiento: por tanto, no para algunos comportamientos. La integridad no se fundamenta en propiedades fortuitas y contingentes de unos ordenamientos individuales, ${ }^{3}$ no subsiste fortui-

3 Un ejemplo de fundamentación de la integridad no válida para todo ordenamiento, es la fundamentación en la así llamada norma general exclusiva (cfr. Norberto Bobbio, Teoria dell'ardinamento giuridico, Torino ${ }_{\star}$ G. Giappichelli, 1960, pp. 148-157):

Según esta fundamentación, hay integridad puesto que hay una norma (justamente la norma general exclusiva) que califica como indiferentes los comportamientos no calificados por otras normas.

Ahora bien, yo reconozco que si existe esta norma y alli donde existe esta norma, hay integridad. Niego, solamente, que esta norma sea válida necesariamente siempre y en todas partes. Es una norma contingente; puede no existir; no es válida necesariamente en todo ordenamiento posible. 
dad y contingencia para unos comportamientos individuales. ${ }^{4}$ Según el principio del tercio excluso, en la hipótesis misma de que un ordenamiento no conste de ninguna norma, todos los comportamientos tienen, sin embargo, un status deóntico: el status de-indiferente, la indiferencia. En virtud del principio del tercio excluso, todo comportamiento que no está calificado es indiferente: está permitida la comisión,-está permitida la omisión.

Si esta fundamentación es lógicamente necesaria, subsiste, necesaria, la integridad para todó ordenamiento y para todo comportamiento. Si un comportamiento está incalificado, en realidad es indiferente, por tanto, tiene él mismo un status deóntico, $\mathrm{Y}$, per definitionem, un ordenamiento es completo si tòdo posible comportamiento tiene un status deóntico.

Formulo la fundamentación de la integridad en el principio del tercio excluso. Según el principio del tercio excluso, dos juicios contradictorios no pueden ser ambos falsos: cuando menos uno es verdadero. Tertium non datur. En especial, este prìncipio es válido para los juicios déónticos contradictorios. Para todo ordenamiento, para todo comportamiento, para todo modo deóńtico, tertium non datur: el juicio, que predica un modo deóntico de un comportamiento, es o verdadero o falso. $O$ es verdadero el juicio mismo o es verdadero el juicio contradictorio. Pára todo ordenamiento, para todo comportamiento (sea ésté calificado, sea ćste incalificado), para todo modo deóntico, o el modo deóntico conviene' al comp̈ortamiento, o el modo deóntico no conviene àl comportamiento. Pára todo comportamiento $C$ y para todo modo deóntico $M$, o $C$ es $M$, o $G$ no es $M$.

La fundamentación en el principio del tercio excluso se cumple para cada uno de los seis modos deónticos ("obligatorio", "prohibido", "imperativo", "permitido", "facultativo", "indiferente"). Uno y único es el resultado de las seis fundamentaciones: los comportamientos incalificados son indiferentes. A partir dél principio del tercio excluso la indiferencia de lo incalificado se prueba, por tanto, de seis maneras.

i. Primera fundamentación. Según el principio del tercio excluso, la comisión de un comportamiento o es obligatoria, o no es obligatoria. Si un comportamiento está incalificado, su comisión no es obligatoria. En efecto,

4 Un ejemplo de fundamentación de la integridad no válida para todò comportamiento es la fundamentación en la interpretación analógica (argumentum a simili). Según esta fundamentación hay integridad puesto "que el intérprete llena, por analogia, las lagunas.

Ahora bien, yo no sólo niego que la fundamentación en la interpretación analógica sea válida para todo ordenamiento (cfr. Amedeó G. Conte "Ricerche' in tema d'interpretazione analogica", Publicazioni dell'Università di Pavia. Studi nelle ścienze giuridiche $e$ sociali, 36,1957 , pp. $37_{-78}$ ), sino que niego también que la interpretación ànalógica instaure integridad para todo comportamiento. Puede no subsistir ninguna analogía entre el comportamiento incalificado y un comportamiento calificado; la analogía no es necesaria, la interpretación analógica no es necesariamente posible para todo comportamiento incalificado: 
si fuese obligatoria, ese comportamiento sería obligatorio, por tanto estaría calificado, lo cual va contra la hipótesis de la incalificación.

Se argumenta de manera análoga con respecto a la omisión. Según el principio del tercio excluso, la omisión de un comportamiento o es obligatoria, o no es obligatoria. Si un comportamiento está incalificado, su omisión no es obligatoria. En efecto, si fuese obligatoria, ese comportamiento estaría prohibido, por tanto estaria calificado, lo cual va contra la hipótesis de la incalificación.

Por consiguiente, de un comportamiento incalificado no son obligatorias ni la comisión ni la omisión. Por tanto, está permitido omitirlo y cometerlo; o sea, están permitidas tanto la omisión como la comisión. Un comportamiento incalificado es indiferente.

ii. Segunda fundamentación. Según el principio del tércio excluso, la comisión de un comportamieṇto o está prohibida, o no está prohibida. Si un comportamiento está incalificado, su comisión no está prohibida. En efecto, si estuviese prohibida, ese comportamiento estaría prohibido, por tanto estaría calificado, lo cual va contra la hipótesis de la incalificación.

De manera análoga se argumenta con respecto a la omisión. Según el principio del tercio excluso la omisión de un comportamiento o está prohibida, o no está prohibida. Si un comportamiento está incalificado, su omisión no está prohibida. En efecto, si estuviese prohibida, ese coḿmortamiento sería obligatorio, por tanto estaría calificado, lo cual va contra la hipótesis de la incalificación.

Por consiguiente, de un comportamiento incalificado no están prohibidas ni la comisión ni la omisión. Por tanto, está permitido cometerlo y omitirlo; o sea, están permitidas tanto la comisión como la omisión. Un comportamiento incalificado es indiferente.

iii. Tercera fundamentación. Según el principio del tercio excluso, un comportamiento o es imperativo (he definido 'imperativo' como ' $u$ obligatorio, o prohibido'), o no es imperativo. Si un comportamiento está incalificado, no es imperativo. En efecto, si éste fuese imperativo, estaría calificado, lo cual va contra la hipótesis.

Por consiguiente, un comportamiento calificado no es imperativo. No imperativo equivale a indiferente. Por tanto, un comportamiento incalificado es indiferente.

iv. Cuarta fundamentación. Según el principio del tercio excluso, la comisión de un comportamiento o está permitida, o no está permitida. Si un comportamiento está incalificado, su comisión está permitida. En efecto, si no estuviese permitida, estaría prohibida; por tanto ese comportamiento estaría prohibido, por consiguiente estaría calificado, lo cual va contra la hipótesis de la incalificación.

De manera análoga se argumenta con respecto a la omisión. Según el 
principio del tercio excluso, la omisión de un comportamiento o está permitida o no está permitida. Si un comportamiento está incalificado, su omisión está permitida. En efecto, si no estuviese permitida, estaría prohibida; por tanto, ese comportamiento sería obligatorio, por consiguiente, estaría calificado, lo cual va contra la hipótesis de la incalificación.

Por consiguiente, de un comportamiento incalificado están permitidaś tanto la comisión como la omisión. Un comportamiento incalificado es indiferente.

v. Quinta fundamentación. Según el principio del tercio excluso, la comisión de un comportamiento o es facultativa, o no es facultativa. Si un comportamiento está incalificado, su comisión es facultativa. En efecto, si no fuese facultativa, sería obligatoria; por tanto ese comportamiento sería obligatorio, por consiguiente estaría calificado, lo cual va contra la hipótesis de la incalificación.

De manera análoga se argumenta con respecto a la omisión. .Según el principio del tercio excluso, la omisión de un comportamiento o es facultativa, o no es facultativa. Si un comportamiento está incalificado, su omisión es facultativa. En efecto, si no fuese facultativa, estaría prohibida; por tanto, ese comportamiento sería obligatorio, por consiguiente estaría calificado, lo cual va contra la hipótesis de la incalificación.

Por consiguiente, de un comportamiento incalificado son facultativas tanto la comisión como la omisión. Por tanto, está permitido no cometerlo y no omitirlo; o sea, están permitidas tanto la omisión como la comisión. Un comportamiento incalificado es indiferente.

vi. Sexta fundamentación. Según el principio del tercio excluso, un comportamiento o es indiferente, o no es indiferente. Si un comportamiento está incalificado, no es indiferente. En efecto, si no fuese indiferente, sería imperativo, o sea, seria u obligatorio o prohibido; por consiguiente estaria calificado, lo cual va contra la hipótesis de la incalificación.

Por consiguiente, un comportamiento incalificado es indiferente.

En virtud de la fundamentación de la integridad en el principio del tercio excluso, se duplican los conceptos de "indiferente", "permitido", "facultativo". Hay comportamientos indiferentes, o permitidos, o facultativos, en razón de que están calificados; hay comportamientos indiferentes, permitidos, facultativos, en razón de que están incalificados. Algunos comportamientos son indiferentes, o permitidos ó facultativos, porque una norma los califica como tales; otros comportamientos, en cambio, son indiferentes, o permitidos, o fácultativos; porque ninguna norma los califica como tales. 


\subsection{Critica de la fundamentación.}

\section{2.o. Introducción.}

El principio del tercio excluso parece, por tanto, garantizar la indiferencia de lo incalificado $\mathrm{y}$, mediante ella, la integridad para todo ordenamiento y para todo comportamiento, aun para el caso límite mismo en que el ordenamiento no conste de ninguna norma. Sobre ese principio parece fundarse, segura, la indiferencia de lo incalificado.

Yo niego que sea así. La indiferencia de lo incalificado, este principio primero, Urgrund de la integridad, no está garantizada por el principio del tercio excluso. El Urgrund no es más que un Ungrund.

Me abstendré de toda crítica en general al principio mismo del tercio excluso, ${ }^{5}$ así como, en especial, me abstendré de limitar su validé a juicios deónticos contradictorios sobre comportamientos incalificados. Me abstendré tanto de una como de otra crítica puesto que este principio, aun cuando es válido en la hipótesis misma de la incalificación, sin embargo no sirve para probar que lo incalificado es.indiferente y para demostrar, así, la integridad de todo ordenamiento.

Consideremos, en efecto, las seis fundamentaciones de la indiferencia de lo incalificado en el principio del tercio excluso. Se dividen en dos grupos de tres. Las primeras tres proceden así: la comisión y la omisión de los comportamientos incalificados no son obligatorias, respectivamente, no están prohibidas, y los comportamientos incalificados no son imperativos, puesto que, si la comisión o la omisión o el comportamiento fuesen así, el comportamiento estaría calificado. Y ello contradiría la hipótesis de la incalificación, o sea la hipótesis de que el comportamiento está incalificado.

Las últimas tres proceden así: la comisión y la omisión de los comportamientos calificados están permitidas, respectivamente, y los comportamientos incalificados son facultativos, son indiferentes, puesto que, si la comisión o la omisión o el comportamiento no fuesen así, el comportamiento estaría calificado. Y ello contradiría la hipótesis de la incalificación, o sea, la hipótesis de que el comportamiento está incalificado.

Las tres primeras fundamentaciones parten, por tanto, de la aserción de que a lo incalificado no conviene un cierto modo deóntico (el modo "obligatorio", en la primera fundamentación; el modo "prohibido", respectivamente, en la segunda; el modo "imperativo", respectivamente, en la tercera).

Las segundas tres fundamentaciones parten, en cambio, de la aserción de que a lo incalificado conviene un cierto modo deóntico (el modo "permi-

5 Sobre la crítica que se- le ha hecho al principio del tercio excluso por parte del intuicionismo de Louitzen E. J. Brouwer y Arend Heyting, véanse las bibliografías, en un principio completas, de The Journal of Symbolic Logic. 
tido", en la cuarta fundamentación; el modo "facultativo", respectivamente, en la quinta; el modo "indiferente", respectivamente, en la sexta).

Yo niego que las seis fundamentaciones fundamenten la indiferencia de lo incalificado $y$, mediante ella, la integridad. "Con mayor propiedad, yo afirmo que ellas o no instauran la integridad, o instauran la contradictoriedad. O lagunas, o antinomias.

\subsubsection{Critica de las tres primeras fundamentaciones.}

Las tres primeras fundamentaciones de la integridad en el principio del tercio excluso o no instauran integridad o instauran contradictoriedad. "

\subsubsection{Prueba' de la no integridad.}

En la hipótesis misma de que el principio del tercio excluso es válido también para los comportamientos incalificados (o sea, para juicios deónticos contradictorios sobre comportamientos incalificados), el principio del tercio excluso dice solamente que, para toda pareja de juicios deónticos contradictorios sobre comportamientos incalificados, tertium non datur: cuàndo menos uno es verdadero. Pero ese principio no dice cuál de ellos es verdadero. Dice que uno de los dos (uter) es verdadero; no dice cuál de los dos (uter?) es verdadero.

Pero admitamos que el principio del tercio excluso sea válido aun en la hipótèsis miśma de la incalificación; admitamos también que pueda decirse cuál de los juicios contradictorios sobre el comportamiento incalificado es vèrdadero; admitamos también que pueda decirse que las comisiones y las omisiones del comportamiento incalificado no son obligatorias, réspéctivamente, no están prohibidas, respectivamente, no son imperativas. Sin embargo, esto no instaura la integridad. 'En esas tres hipótesis mismas, permanece la no integridad. En efecto, todo lo que sabemos acerca del comportamiento incalificado es que a su comisión y a su 'omisión no convienen ciertos modos deónticos; sabemos que ellas no son obligatorias, no están prohibidas, no son imperativas. Pero no sabemos si a ellas conviene un modo deóntico y cuál sea éste. Sabemos, en suma, lo que lo incalificado no es; ignoramos, sin embargo, qué es. Sabemos que su comisión no es obligatoria; ignoramos si es facultativa. Sabemos que su omisión no es obligatoria; ignoramos si es facultativa. Sabemos que su comisión no está prohibida; ignoramos`si está permitida; y así succsivamente.

Lá no integridad, por tanto, permanece. Hay integridad si del mismo comportamiento calificado puede decirse qué es, qué modo le conviene, cuál es su status deóntico. No hay integridad si de lo incalificado solamente puede decirse qué no es, qué modo no le conviene, cuál no es su status, deóntico. 
A fin de que de la verdad de los juicios deónticos negativos sobre el comportamiento incalificado ('La comisión del comportamiento incalificado no es obligatoria', y así sucesivamente) se derive la indiferencia de lo incalificado y, mediante ella, la integridad necesaria de todo ordenamiento, debe ser satisfecha una condición ulterior: la negación de un juicio deóntico debe ser, a su vez, un ulterior juicio deóntico, inclusive en la hipótesis misma de la incalificación. ${ }^{6}$ (En nuestro caso, es necesario que el juicio 'La comisión del comportamiento incalificado no es obligatoria' equivalga a 'La comisión del comportamiento obligatorio es facultativa' y así sucesivamente.) Yo negaré ( $s u b$ 2.2) que esta condición esté satisfecha; negaré que la negación de un juicio deóntico sobre un comportamiento incalificado sea ella misma otro juicio deóntico. ${ }^{7}$ De todas maneras, aun cuando fueșe así, súrgirían antinomias, surgiría contradictoriedad.

\subsubsection{Prueba de la contradictoriedad.}

Si los juicios deónticos negativos sobre el comportamiento incalificado 'La comisión del comportamiento incalificado no es obligatoria' y así suce-

6 Sobre la negación de las normas cfr., entre otros escritos, Erik Ahlman, "Saamisen käsitteen suhde pitämisen käsitteeseen", Ajatus, 11, 1942, pp. 5-19; Robert Blanché, "Quantity, Modality and Other Kindred Systems of Categories", Mind, New Series, '51, 1952, pp. 369-375; Idem, "Sur l'opposition des concepts", Theoria, 19, 1953, pp. 89-130; Idem, "Opposition et négation", Revue Philosophique de la France et de l'Étranger, 147, 1957, pp. 187-216; Idem, "Sur la structuration du tableau des connectifs interpropositionnels", The Journal of Symbolic Logic, 22, 1957, pp. 17-18; Norberto Bobbio, "Diritto e logica", Rivista Internazionale di Filosofia del Diritto, terza serie, 39, 1962, pp. 11-44, pp. 39-41; Manfred Moritz, Uber Hohfelds System der juridischen Grundbegriffe, Lund, CWK Gleerup; Köbenhavn, E. Munksgaard, 1960; Jerzy Sztykgold, "Negacia normy", Przeglad Filozoficzny, 39, 1936, pp. 492-494; Ota Weinberger, "Über die Negation von Sollsätzen", Theoria, 29, 1957, pp. 102-192; Georg Henrik von Wright, On the Logic of Negation, Köbenhavn, E. - Munksgaards Forlag, Helsinki, Academic Bookstore, Helsingfors, Northern Antiquarian Bookstore, 1959 ("Societas scientiarum fennica", Commentationes physico-mathematicae, 22, 4).

M. Moritz, op. cit., p. 114 , menciona, con lagunas, otros dos escritos que no he podido leer. Transcribo las indicaciones de Moritz: George W. Goble, "Affirmative and Negative Legal Relations", Illinois Law Quarterly, 4, 1922, número 2; Idem, Negative Legal Relations Re-Examined, ibidem, 5, 1922, número 1 .

7 Sobre el principio del tercio excluso en - la lógica de las proposiciones normativas cfr., entre otros escritos, Eduardo Garcia Máynez, "Los principios jurídicos de contradicción y de tercero excluido", Filosofía y Letras, 19, 1950, pp. 47-62; Idem, Introducción a la lógica jurtdica, México-Buenos Aires, Fondo de Cultura-Económica, 1951; Idem, Los Principios de la ontologia formal del Derecho y de la lógica jurídica, México, Universidad Nacional de México, 1955, ensayo reèditado en Idcm, Ensayos filosófico-jurídicos, Xalapa; México, Universidad Veracruzana, 1959, pp. 221-243, traducción alemana "Die. höchsten Prinzipien der formalen Rechtsontologie und der juristischen Logik, Archiv für Rechtsund Sozial-philosophie, 45, 1959, Pp. 1932214.

Sobre el principio del tercio excluso en los escritos de ética de Edmund Husserl cfr. Alois Roth, Edmund Husserls ethische Untersuchungen, Den Haag, M. Nijhoff, 1959, pp. 79-82. 
sivamente, son verdáderos, también lo son los juicios deónticos negativos sobre el comportamiento incalificado 'La comisión del comportamiento incalificado no está permitida', 'La comisión del comportamiento incalificado no es facultativa', 'La omisión del comportamiento incalificado no está permitida', y así sucesivamente.

La verdad de los dos grupos de juicios negativos no instaura, en sí misma, ni la integridad ni la contradictoriedad. Dice, en efecto, qué nó es lo incalificado; no se dice qué sea.

Esos juicios instauran la integridad y la contradictoriedad si se interpretan como equivalentes a juicios deónticos positivos, o sea, si se asume la equivalencia entre 'La comisión dél comportamiento incalificado no es obligatoria' y 'La comisión del comportamiento incalificado es facultativa'; la equivalencia entre 'La comisión de lo incalificado no es facultativa' y 'La comisión de lo incalificado es obligatoria', y así sucesivamente. A la comisión y a la omisión del comportamiento incalificado convienen simultáneamente todos los modos deónticos; por tanto, al comportamiento incalificado convienen todos los modos deónticos. Éste es obligatorio y facultativo, prohibido y permitido, imperativo e indiferente. Su comisión está permitida y no permitida; su omisión está permitida y no permitida.

Lo cual es contradictorio, es una antinomia.

\subsubsection{Conclusión de la critica.}

Las primeras tres fundamentaciones de la indiferencia de lo incalificado ( $y$, mediante ella, de la integridad) en el principio del tercio excluso, o no instauran la integridad, o instauran la contradictoriedad; o dejan las lagunas, o generan antinomias.

O lagunas, o antinomias. El dilema es neto: o lo incalificado no tiene ningún status deóntico (su comisión y su omisión no tienen ninguna calificación deóntica), o lo incalificado tiene cualquier status deóntico (su comisión y su omisión tienen todas las calificaciones deónticas).

\subsubsection{Critica de las últimas tres fundamentaciones.}

Las últimas tres fundamentaciones de la integridad en el principio del tercio excluso o no instauran integridad, o instauran contradictoriedad.

\subsubsection{Prueba de la no integridad.}

En la hipótesis misma de que el principio del tercio excluso es. válido también para los comportamientos incalificados (o sea, para juicios deónti$\cos$ contradictorios sobre comportamientos incalificados), el principio del 
tercio excluso dice solamente que, para toda pareja de juicios deónticos contradictorios sobre comportamientos incalificados, tertium non datur: cuando menos uno es verdadero. Pero ese principio no dice cuál de ellos es verdadero. Dice que uno de los dos (uter) es verdadero; no dice cuál de los dos (uter?) es verdadero.

Pero admitamos que el principio del tercio excluso sea válido aun en la hipótesis misma de la incalificación; admitamos también que pueda decirse cuál de los juicios contradictorios sobre el comportamiento incalificado es verdadero. Sin embargo, aun en estas hipótesis es falso que la comisión y la omisión del comportamiento incalificado estén permitidas, respectivamente, sean facultativas; respectivamente, sean indiferentes. Estas, tres últimas fundamentaciones en el principio del tercio excluso proceden así: la comisión del comportamiento incalificado o está permitida o no está permitida; la comisión del comportamiento incalificado o es facultativa o no es facultativa, y así sucesivamente. Ahora la comisión está permitida, pues, si no estuviese permitida, estaría prohibida; lo cual contradiría la hipótesis de la incalificación. Análogamente, ella es facultativa, pues, si no fuese así, sería obligatoria; lo cual contradiría la hipótesis; y así sucesivamente. Pero esta demostración per absurdum es falsa. "Permitido", "facultativo", "indiferente", son también modos deónticos; por tanto, por el mismo motivo por el cual la comisión de lo incalificado no es obligatoria, no está prohibida, y así sucesivamente, la comisión de lo incalificado no está permitida, no es facultativa, y así sucesivamente.

La no integridad, por tanto, permanece.

\subsubsection{Prueba de la contradictoriedad.}

Si, en cambio, se asume que la comisión del comportamiento incalificado está permitida, que la comisión del comportamiento incalificado es facultativa, y así sucesivamente, entonces, con el mismo título, la comisión de lo incalificado es obligatoria, está prohibida, y así sucesivamente. A la comisión y a la omisión del comportamiento incalificado convienen simultáneamente todos los modos deónticos; por tanto, al comportamiento incalificado le convienen todos los modos deónticos. Éste es obligatorio y facultativo, prohibido y permitido, imperativo e indiferente. Su comisión está permitida y no permitida; su omisión está permitida y no permitida.

Lo cual es contradictorio, es una antinomia.

\subsubsection{Conclusión de la critica.}

En lo que toca a las tres últimas fundamentaciones de la indiferencia de lo incalificado ( $y$, mediante ella, de la integridad) en el principio del tercio excluso, son válidas las mismas conclusiones relativas a las tres pri- 
mèras fundamentaciones; o no instauran integridad;"o instauran contradictoriedad.

O lagunas, o ancinomias. El dilema es neto: o. lo incalificado no tiene niñún status deóntico (su comisión y su omisión no tienen ninguna calificación déntica), o lo incalificado tiene cualquier status deóntico (su comisión y su omisión tịenen todas las calificaciones deónticas).

2. La fundamentación de la integridad en la lógica déntica.

\subsection{La fundamentación.}

Así como la integridad parecería subsistir necesaria y a priori para todo ordenamiento y para todo comportamiento debido a la fundamentación en el principio del tercio exclúso, así también lo parecería debido a la fundamentảción en la lógica deóntica misma. Según esta segunda fundamentación, en la hipótesis misma de que un ordenamiento no conste de ninguna norma, todos los comportamientos tienen, sin embargo, un status deóntico: el status de indiferente, la indiferencia.

Fórmulo la-fundamentación de la integridad en la lógica deóntica. Si un comportamiento está incalificado; no es obligatorio, ni prohibido, ni imperativo. Ahora (son verdades de la lógica deóntica), el juicio según el cual un comportamiento no es obligatorio, equivale al juicio según el cual ese comportamiento es facultativo; el juicio šegún el cual un comportamiento no está prohibido, equivale al juicio según el cual ese comportamiento está permitido; el juicio según el cual no es imperativo, equivale al juicio según el cual ese comportamiento es indiferente.

Ahora bien, los comportamientos incalificados no son obligatorios; por tanto, son facultativos; no están prohibidos, por tanto, están permitidos; no son imperativos, por tanto, son indiferentes. Puesto que un comportamien. tó facultativo y permitido es indiferente, se dirá, con mayor brevedad, que los comportamientos incalificados son indiferentes.

\subsection{Critica de la fundamentación.}

2.2.o. Introducción.

La lógica deóntica parecé, por consiguiente, garantizar la indiferencia de lo incalificado $y$, mediante ella, la integridad de todo ordenamiento y de todo comportamiento, inclusive en el caso límite mismo en que el ordenamientò no conste dé ninguna norma. Sob̆re esta lógica parece fundamentarse, segura, la indiferencia de lo incálificado:-

Yo niego, sin .embargo, que sea así. La indiferencia de to incalificado, este Urgrund de la integridad, no está garantizada ni siquiera por la lógica deóntica misma.

Yo niego que esta fundamentación fundamente la indiferencia de lo inca- 
lificado $y$, mediante ella, la integridad. Más propiamente, yo afirmo que ella o no instaura integridad, o instaura contradictoriedad. O lagunas, o antinomias.

En efecto, son dos las posibles concepciones de la negación de los juicios deónticos sobre comportamientos incalificados (en otros términos, puede interpretarse de doble manera la negación en juicios como 'El comportamiento incalificado no es obligatorio', 'El comportamiento incalificado no está prohibido', y así sucesivamente). La negación puede concebirse o como negación débil o como negación fuerte: ${ }^{8}$

\subsubsection{Prueba de la no integridad.}

Si la negación es débil, la negación de un juicio deóntico sobre un comportamiento incalificado no es, a su vez, un ulterior juicio deóntico. La negación 'El comportamiento incalificado no es obligatorio', por ejemplo, significa solamente que el comportamiento incalificado no es obligatorio, no que sea facultativo. Análogamente por lo que toca a los modos "prohibido" e "imperativo".

Por consiguiente la no integridad permanece. Hay integridad si del mismo comportamiento incalificado puede decirse qué es, qué modo le conviene, cuál es su status deóntico. No hay integridad si de lo incalificado puede decirse solamente qué no es, qué modo no le conviene, cuál no es su status deóntico.

\subsubsection{Prueba de la contradictoriedad.}

Si la negación es fuerte, la negación de un juicio deóntico sobre un comportamiento incalificado es, a su vez, un ulterior juicio deóntico. La negación 'El comportamiento incalificado no es obligatorio', por ejemplo, equivale al juicio deóntico 'El comportamiento incalificado es facultativo'. Análogamente por lo que toca a los modos "prohibido" e "imperativo".

Ahora bien, yo niego que (en la hipótesis de que el comportamiento estć incalificado) la negación de un juicio deóntico sea un juicio deóntico (o sea, niego que la negación sea fuerte).

Ésta es mi crítica: las dos implicaciones materiales de la forma 'Si el comportamiento $C$ no es $M /, C$ es $M / /$ ', y 'Si el comportamiento $C$ no es $M / /, G$ es $M /$ ', equivalen a la disyunción 'O el comportamiento $C$ es $M /$, o el comportamiento $C$ es $M / /$ '. Ahora bien, una disyunción es verdadera si cuando menos uno de sus argumentos es verdadero. En particular, una disyunción de la forma ' $\mathrm{O}$ el comportamiento $C$ es $M /$, o el comportamiento $C$ es $M / /$ ' es verdadera si es verdadero ' $\mathrm{El}$ comportamiento $C$ es $M /$ ', o si es verdadero 'El comportamiento' $C$ es $M / /$ '.

8 Cfr. G. H. von Wright, On the Logic of Negation, op. cit., pp. 26-27. 
Sea, ahora, un comportamiento incalificado $C /$. Yo niego que disyunciones de la forma ' $O$ el comportamiento $C$ es $M /$, o el comportamiento $C$ es $M / /$ ' sean válidas también para los comportamientos incalificados. En otros términos, niego que sea verdadero ' $O$ el comportamiento incalificado $C$ es $M /$, o el comportamiento incalificado $C$ es $M / /$ '.

En efecto, esta disyunción sería verdadera si cuando menos uno de sus argumentos fuese verdadero. Pero ninguno de sus argumentos es verdadero. Aporto dos pruebas, alternativas, de esta tesis.

i. Primera prueba. Si $\mathrm{C} /$ está incalificado, no puede verificarse cuál sea su calificación deóntica. Todo juicio sobre la calificación deóntica de $C /$ no es, por tanto, ni verdadero ni falso. (Según el principio de verificación, el significado de un juicio es el método de su verificación.). En particular, no son ni verdaderos ni falsos los dos argumentos de la disyunción ' $O$ el comportamiento incalificado $C$ es $M /$, o el comportamiento incalificado $C$ / es $M / /$ '. Si ambos argumentos no son ni verdaderos ni falsos, ninguno de ellos es verdadero. Puesto que ninguno de los argumentos es verdadero, la disyunción es falsa.

ii. Segunda prueba. Si (en contra de la tesis que se acaba de afirmar) se niega que ambos argumentos de la disyunción no son ni verdaderos ni falsos, ambos son falsos. En efecto, si uno de ellos fuese verdadero, el comportamiento incalificado $C /$ sería incalificado, lo que contradiría la hipótesis de la incalificación. Si ambos argumentos son falsos, ninguno de ellos es verdadero. Puesto que ninguno de los argumentos es verdadero, la disyunción es falsa.

En ambas hipótesis, por consiguiente (se afirme o se niegue que los dos argumentos de la disyunción no son ni verdaderos ni falsos), ninguno de los dos argumentos es verdadero por lo que respecta a los comportamientos incalificados. Ningún argumento es verdadero en la primera hipótesis, puesto que arnbos argumentos no son ni verdaderos ni falsos; ningún argumento es verdadéro en la segunda hipótesis, puesto que ambos argumentos son falsos.

Si la disyunción es falsa ( $y$ es falsa), son falsas las implicaciones materiales de la forma 'Si el comportamiento incalificado $C /$ no es $M /, C /$ es $M / /$ '. En particular, son falsas las implicaciones ' $\mathrm{Si}$ ' un comportamiento incalificado no es obligatorio, es facultativo'; ' $\mathrm{Si}$ un comportamiento inca. lificado no está prohibido, está permitido'; 'Si 'un comportamiento incalificado no es imperativo, es indiferente'. Por tanto, es falso que los comportamientos incalificados (en cuanto no son obligatorios, no están prohibidos, no son imperativos) sean facultativos, están permitidos, sean indiferentes (o, con mayor brevedad, indiferentes).

Si (en contra de mi crítica) se asume que tales implicaciones son verdaderas aun para los comportamientos incalificados, se incurre en una antinomia, surge la contradictoriedad. 
En efecto, así como los comportamientos incalificados no son obligatorios, por tanto son facultativos; no están prohibidos, por tanto, están permitidos; no son imperativos, por tanto son indiferentes, asi, por consiguiente, con el mismo título, los comportamientos incalificados no son facultativos, por tanto son obligatorios; no están permitidos, por tanto están prohibidos; no son indiferentes, por tantó son imperativos. A la comisión y a la omisión del comportamiento incalificado convienen simultáneamente todos los modos deónticos; por consiguiente al comportamiento incalificado convienen todos los modos deónticos. Este es obligatorio y facultativo, prohibido y permitido, imperativo e indiferente. Su comisión está permitida y no permitida; su omisión está permitida y no permitida.

Lo cual es contradictorio, es una antinomia.

\subsubsection{Conclusión de la crítica.}

Por lo que respecta a la fundamentación de la indiferencia de lo incalificado (y, mediante ella, de la integridad) en la lógica deóntica, son válidas las mismas conclusiones a las que se llegó a propósito de la fundamentación en el principio del tercio excluso: o no instaura integridad, o instaura contradictoriedad.

O lagunas, o antinomias. El dilema es neto: o lo incalificado no tiene ningún status deóntico (su comisión y su omisión no tienen ninguna calificación deóntica), o lo incalificado tiene cualquier status deóntico (su comisión y su omisión tienen todas las calificaciones deónticas).

\section{Conclusión. 9}

Ya sea por lo que toca a la fundamentación de la indiferencia de lo incalificado ( $y$, mediante ella, de la integridad) en el principio del tercio

9 Para una bibliografía sobre el tipo de cuestiones que se tocan aquí, véase Amedeo G. Conte, "Bibliografia di logica giuridica, 1936-1960", Rivista Internazionale di Filosofia del Diritto, terza serie, 38, 1961, pp. 120-144; Addenda, ibidem, terza serie, 39, 1962, pp. 45* 46; Idem, "Bibliography of Normative Logic", 1936-1g69, Modern Uses of Logic in Law, 4, 1962, June, pp. $89-100$.

De lo que ha salido después de 1960, recuerdo: Leo Apostcl, Logika en geesteswetenschappen, Brugge, Sinte-Catharina Drukkerij, 1959, p. 173 (Rijksuniversiteit te Gent, 123e Afl.); Fernando Bertolini, "Logica proposizionale e teoria degli insiemi, metamatematica e topologia", en varios, Atti del convegno nazionale di logica (Torino, 5-7 aprile, 1961), Torino Libreria' editrice universitaria Levrotto e Bella, 1961, pp. 41-53, en especial las pp. 52-53; Evert Willem Beth, "Observations Concerning Computation, Deduction and Heuristics", en Varios, Compte- rendu des trataux effectués par. l'Université de Amsterdam dans le cadre de contrat Euratom, (sin lugar, editor, año: pero 1961 o 1962), las pp. 106119, en especial las pp. 117-119; Norberto Bobbio, "Diritto e logica", Rivista Internazionale di Filosofia del Diritto, terza serie, 39, 1962, pp. 11-44; Karl Döhmann, "Die sprachliche Darstellung der Modalfunktoren", Logique et analyse, nouvelle série, 4, 1961, pp. 55-91; 
excluso, ya sea por lo que toca a la fundamentación en la lógica deóntica misma, el resultado es uno: o no integridad, o contradictoriedad; o lagunas, $o$ antinomias.

O los comportamientos incalificados no tienen ningún status deóntico, o los comportamientos incalificados tienen cualquier status deóntico.

(Trad. de Alejandro Rossi.)

Amedeo G. Conte

Universidad de Turín

P. B. Downing, "Opposite Conditionals and Deontic logic", Mind, New Series, 70, 196r, pp. 491-502; Mark Fisher, "A Logical Theory of Commanding", Logique et analyse, nouvelle série, 4, 1961, pp. 154-169; Idem, "A Three-Valued Calculus for Deontic Logic", Theoria, 27, 1961, pp. 107-118; Idem, "A System of Deontic-Alethic Modal Logic", Mind, New Series, 71, 1962; pp. 23x-236; Idem, "On a So-Called Paradox of Obligation”, The Journal of Philosophy, 59, 1962, número, 1, pp. 23-26; Alessandro Giuliani, Il concétto di prova. Contributo alla logica giuridica, Milano, A. Giuffè 1961, pp. XX-264; Stefan Grzybowski, Wypowiedz normatywna oraz jej struktura formalna, Kraków, Nakladem Uniwersytetu Jakiellonskiego, 1961, p. 155 ("Zeszyty Naukowe Universytetu Jagiellonskiego. Rozprawy i

- Studia", 39) (con resúmenes en ruso y en inglés); A. G. Guest, "Logic in the Law", en varios, Oxford Essays in Jurisprudence: A Colaborative Work Edited by A. G. Guest, Oxford, Oxford University Press, 1961, pp. XVIII-292, pp. 176-197; Omar Khayyam Moore, Alan Ross Anderson, "Some Puzzling Aspects of Social Interaction", The Review of Metaphysics, 15, 1962, pp. 409-433; Fritz Paradies, Sic et non, Amsterdam, (sin mención del editor; editado por el autor), 1961, p. 20, p. 12; Idem, Zwei rechts" "wissenschafliche" Aufsätze, Amsterdam, (sin mención del edior; editado por el autor), 1961, p. 8; Nelson Pike, "Rules of Inference in Moral Reasoning", Mind, New Series, 7o, 1961, pp. 391-399; Avelino Manuel Quintas, "Possibilitá e limiti della logica giuridica", Rivista Internazionale di Filosofia del Diritto, terza serie, 39, 1962, pp. 403-407; Beniamino Scucces Muccio, "Il principio di correlazione nel campo della logica giuridica", Rizista Internazionale di Filosofia del Dirillo, terza serie, 38, 1961, Pp. 715-723; varios, Le fait et le droit. Etudes de Logique juridique, Bruxclles, Etablissements Emile Bruylant, 1961, p. 278; editado también en Dialectica, 15,1961 , pp. 337-6io. 


\section{BIBLIOGRAFIA}

La presente bibliografía cubre el decenio 1951-196o. Se limita a la lógica deóntica; para una bibliografía de la lógica de las proposiciones normativas en general cfr. Amedeo G. Conte, "Bibliografia di logica giuridica", 1936-1960. Rivista Internazionale di Filosofia del Diritto, Terza serie, 38, 1961, pp. 120-144, y en Atti del $V$ congresso nazionale di filosofia del diritto, al cuidado de Rinaldo Orecchia. Milán, Dr. A. Giuffre, 1961; p. 144, pp. 120 144; Amedeo G. Conte, "Bibliography of Normative Logic, 1936-196o", Mull.

La presente bibliografía consta de dos bibliografías: alfabética, por el nombre del autor, y cronológica, por el año de la edición.

La primera clasifica los escritos en orden alfabético, por el nombre del autor; más las obras del mismo autor, en orden cronológico, por el año de la edición; más las obras de un mismo autor y año, en orden alfabético, por el título.

La segunda clasifica los escritos en orden cronológico, por el año de la edición; más las obras del mismo año, en orden alfabético, por el nombre del autor; más las obras de un mismo autor y año, en orden alfabético, por el título.

Amedeo G. Conte.

Bibliografía de lógica deóntica. 195 1-1960.

1. Bibliografia en orden alfabético.

Állen, Layman Edward.

1. "Deontic Logic", Mull, 2, 1960, pp. 13-27.

Anderson, Alan Ross.

2. The Formal Analysis of Normative Concepts: New Haven (Connecti: cut), 1956, pp. VI-99. (Technical Report No. 2, Office of Naval Research Contract No. SAR/Nonr-6og (16), Group Psychology Branch.)

3. "Reduction of Deontic Logic to Alethic Modal Logic". The Journal of Symbolic Logic, 22, 1957, p. 105.

4. Alan Ross Anderson, Omar Khayyam Moore, "The Formal Analysis of Normative Concepts", Ámerican Sociological Review, 22, 1957, pp. 9-17.

5. "A Reduction of Deontic Logic to Alethic Modal Logic", Mind, New Series, 67, 1958, pp. 100-103.

6. "The Logic of Norms", Logique et analyse, nouvelle série, 1, 1958, páginas $84-91$.

7. "On the Logic of 'Commitment'", Philosophical Studics, 10, 1959, páginas $23-27$. 
Apostel, Leo.

8. "Game Theory and the Interpretation of Deontic Logic", Logique et analyse, nouvelle série, 3, 1960, pp. 70-9o.

Becker, Oskar.

9. Untersuchungen über den Modalkalkül, Meisenheim am Glan, Westkulturverlag Anton Hain, 1952, p. 87.

Berg, Jan.

10. "A note on Deontic Logic", Mind, New Series, 69, 196o, pp. $5^{66-567}$.

Blanché, Robert.

11. "Quantity, Modality and Other Kindred Systems of Categories", Mind, New Series, 61, 1952, pp. 369-375.

12. “Sur l'opposition des concepts", Theoria, 19, 1953, pp. 8g-13o.

13. "Opposition et 'négation", Reyue. Philosophique de la France è de l'Etranger, 147, 1957, pp. 187-216.

14. "Sur la structuration du tableau des connectifs interpropositionnels binaires", The Joumal of Symbolic Logic, 22, 1957, pp. 17-18.

Bobbio, Norberto.

15. "La logica giuridica di Eduardo García Máynez", 'Rivista Internazionale di Filosofia del Diritto, Terza serie, 30, 1954, pp. 644-669. "Traducción castellana de Luis Recaséns Siches: "La lógica jurídica de Eduardo García Máynez", México, Universidad Nacional de México, 1956, p. 24 ("Suplementos del Seminario de Problemas Científicos y Filosóficos", 5.)

Castañeda, Héctor Neri.

16. "La lógica general de las normas y la ética. (Ésbozo de una teoría.)" Universidad de San Carlos (Guatemala), (sin indicación del volúmen), - 1954, n. 3o, pp. 129-196.

17. "A Note on Imperative Logic", Philosophical Studies, 6, 1955, pp. 1-4.

18. "Nota sobre la lógica de los fines y medios", Universidad de San Carlos (Guatemala), (sin indicación del volumen), 1956, n. 39, pp. 63-75.

19. "A 'Theory of Morality", Philosophy and Phenomenological Research, i7, $1957^{-1958, ~ p p . ~ 339-352 . ~}$

20. "On the Logic of Norms", Methodos, 9, 1957, pp. 209-215.

21. "Un sistema general de lógica normativa", Dianoia, 3, 1957, pp. 303-333.

22. "Imperatives and Deontic Logic", Analysis, 19, 1958, pp. 42-48.

23. "The Logic of Obligation", Philosophical Studies, 10, 1959, pp. 17-23.

24. "Obligation and Modal (Logic", Logique et analyse, nouvelle série, 3, ig6o, pp. 40-48.

25. "'Ought' and Assumption in Moral Philosophy", The Journal of Philosophy, 57, 196o, pp. 791-803.

26. "Imperative Reasonings", Philosophy and Phenomenological Research, $21, \cdot 19^{60-1961, ~ p p . ~ 21-49 . ~}$

Dawson, Edward E. 
27. "A Model for Deontic Logic", Analysis, 19, 1959, pp. 73-78.

Fenstad, Jens Erik.

28. "Notes on Normative Logic", Oslo, I Kommisjon Hos H. Aschehoug \& Co. (W. Nygaard), 1959, p. 25. ("Avandlinger utgitt av Det Norske Videnskaps-Akademi i Oslo", II. Historisk-filosofisk klasse, 1959, 1.)

Feys, Robert.

29. "Expression modale du 'devoir-être",, The Journal of Symbolic Logic, 20, 1955, pp. 91-92.

3o. (Respuesta a: A. N. Prior, "A Note on the Logic of Obligation"), Revue Philosophique de Louvain, troisième série, 54, 1956, pp. 88-89.

García Máynez, Eduardo.

31. "La lógica" deóntica de G. H. von Wright y la ontología formal del derecho", Revista de la Facultad de Derecho de México, 3, 1953, pp. 9-37. Reeditado en: E. García Máynez, Ensayos filosófico-juridicos, pp. 185-219.

32. Los principios de la ontologia formal del derecho y su expresión simbólica, México, Imprenta universitaria, 1953, p. 173. ("Cultura mexicana", 12.)

33. Principios supremos de la ontología formal del derecho y de la lógica jurídica. México, Universidad Nacional de México, p. 14. ("Seminario de problemas científicos y filosóficos", 1955, 54) Reeditado en: E. García Máynez, Ensayos filosófico-jurídicos, pp. 221-243. Traducción alemana: "Die höchsten Prinzipien der formalen Rechtsontologie und der juristischen Logik". Archiv für Rechts- und Sozialphilosophie, XLV, 1959, pp. 193-2 14.

34. Ensayos filosófico-juridicos. Xalapa, México, Universidad Veracruzana, 1959, p. 382. ("Biblioteca de la Facultad de Filosofía y' Letras", 3.)

35. "Ontologia formal del derecho y lógica jurídica”, en: E. García Máynez, Ensayos filosófico-juridicos, pp. 331-343.

Geach, Peter T.

$3^{6 .}$ "Imperative and Deontic Logic", Analysis, 18, 1958, pp. 49-56.

Hintikka, K. Jaakko J.

37. Quantifiers in Deontic Logic. Helsingfors, 1957, p. 23. ("Societas scientiarum fennica", Commentationes humanarum litterarum, XXIII, 4.)

Kalinowski, Jerzy.

38. "Tehria zdan normatywnych" (Teoria de las proposiciones normativas), Studia logica, I, .1953, pp. 113-146. Errata. Ibidem, Errata, pp. 1-2 n. n. Traducción francesa: Théorie des propositions normatives. Ibidem, pp. 147-182. Errata. Ibidem, Errata, p. 2 n. n. Resumen en ruso: Teorija normativnyh predlozenij. Ibidem, pp. $183-184$.

Lemmon, E. J.

39. E. J. Lemmon, P. H. Nowell-Smith, "Escapism: the Logical Basis of Ethics", Mind, New Series, 69, 196o, pp. 289-300. 
McLaughlin, R، N.

40. "Further Problems of, Derived Obligation", Mind, New Series, 64, 1955, pp. 400-402.

Meredith, David.

41. "A Correction to von Wrigth's Decision Procedure for the Deontic System P", Mind, New 'Series, 65, 1956, pp. 548-550.

Moore, Omar Khayyam.

42. Alan Ross Anderson, Omar: Khayyam Moore, "The Formal 'Analysis of Normative Concepts", American Sociological Review, 22, 1957; pp. 9-i 7 .

Nowell-Smith, P. H.

43. E. J. Lemmon, P. H. Nowell-Smith, "Escapism: the Logical Basis of Ethics", Mind, New Series, 69, 196o, pp. $289-900$.

Prior, Arthur N.

44. "The Paradoxes of Derived Obligation", Mind, New Series, 63, 1,954, pp. $64-65$.

45. Formal logic, Oxford, at the Glarendon Press, 1955, p. 329. (P. 220229.)

46. "A Note on the Logic of Obligation", Revue Philosophique de Louvain, troisième sćrie, 54,1956 , pp.' $86-87$.

47. Time and Modality. Oxford, at the Clärendon Press, 1957, pp. VIII-148. pp. 140-145. (Appendix D. Modal and Deontic Logic.)

48. "Escapism: the Logical Basis of Ethics", en: Essays in Moral Philosophy. pp. $135^{-1} 4^{6}$. Edited by A. I. Melden, Seattle, University of Washington Press, 1958, pp. XII-2 16.

Rescher, Nicholas.

49. "An Axiom System for Deontic Logic", Philosophical Studies, 9, 1958 , pp. 24-9o. Corrigenda, Ibidem, p. 64.

Tammelo, Ilmar.

50. "On the Logical Openness of Legal Orders. A Modal Analysis of Law with Special Reference to the Logical Status of Non Liquet in International Law", The American Journal of Comparative Law, 8, 1959, pp. 187-203.

51. "Axiomatics of Systems of Law and the Logical Bounds of Juristic Thinking”, 'Oigusteaduslik ajakiri (sin indicación del volumen), 196o, n. 6, pp. 47.

Visalberghi, Aldo.

52. "Forma logica e contenuto empirico negli enunciati" valutativi. I. La logica degli imperativi e delle norme", Rivista di filosofia, 47, 1956, Pp. 424-453; II. "Valutazione e 'transazione"', Ibidem, 48, 1957, Pp. 382$415 ; 49,1958$, pp. 38-68. Reeditado en: A. Visalberghi, Esperienza $e$ valutazione, pp. $37^{-130}$.

53. Esperienza e volutazione. Torino, Taylor, 1958, p. 214. ("Documenti e ricerche. Biblioteca di cultura contemporanea".) 
Weinberger, Ota.

54. "Théorie des propositions normatives. Quelques remarques au sujet de l'interprétation normative des systèmes $\mathbf{K}_{1}$ et $\mathbf{K}_{2}$ de $\mathbf{M}$. Kalinowski", Studia logiça, 9, 1960, pp. 7-21. Resumen en "polaco: Teoria zdan normatywnych (Streszczenie.) Ibidem, pp. 22-23. Resumen en ruso: Teorija normationyh predlozenij (Rezjume.) Ibidem, pp. 24-25.

Wright, von, George Henrik.

55. An Essay in Modal Logic. Amsterdam, North-Holland Publishing Company, 1951, pp. VI-9o ("Studies in Logic and the Foundations of Mathematics".)

56. "Deontic Logic", Mind, New Series, 6o, 1951, p. 1-15. Reeditado en: G. H. von Wrigth, Logical Studies, pp. 58-74.

57. "On the Logic of Some Axiological and Epistemological Concepts", Ajatus, 17, 1952, pp. 213-234.

$5^{8}$. "Om s. k. praktiska slutledningar" (Sobre las llamadas deducciones prácticas), Tidsskrift for Rettsvitenskap, 68, 1955, pp. $465-495$.

59. "A Note on Deontic Logic and Derived Obligation", Mind, New Series, 65,1956 , pp. $5^{\circ} 7-509$.

6o. Logical Studies, London, Routledge and Kegan Paul, 1957, pp. IX-195.

61. On the Logic of Negation, Köbenhavn, Ejnar Munksgaards Forlag, Helsinki, Academic Bookstore, Helsingfors, Northern Antiquarian Bookstore, 1959, p. 3o. ("Societas scientiarum fennica", Commentationes physico-mathematicae, XXII, 4 .

2. Bibliografía en orden cronológico.

I95I. $55,5^{6}$.

1952. $9,11,57$.

1953. 12, 31, 32; 38 .

$1954.15,16,44$.

1955. $17,29,33,40,45,5^{8}$.

1956. 2, 18, 30, 41, 46, 52, 59 .

$1957.3,4,13,14,19,20,21,37,42,47,60$.

1958. 5, 6, 22, 36, 48, 49, 53.

1959. $7,23,27,28,34,35,50,61$.

1960. 1, $8,10,24,25,26,39,43,51,54$. 